\title{
Comparative study of acid and basic catalysis in microwave assistance of Willgerodt-Kindler reaction for thiobenzamides and derivatives synthesis
}

\author{
Finagnon H. AGNIMONHAN ${ }^{1}$, Léon AHOUSSI ${ }^{1,2}$, Salomé D. S. KPOVIESSI ${ }^{1,3^{*}}$, \\ Fernand A. GBAGUIDI ${ }^{1,2}$, Coco N. KAPANDA ${ }^{3}$, Mansourou MOUDACHIROU ${ }^{2}$, \\ Jacques POUPAERT ${ }^{3}$ and Georges C. ACCROMBESSI ${ }^{1}$ \\ ${ }^{1}$ Laboratory of Physic and Synthesis Organic Chemistry (LaCOPS), University of Abomey-Calavi, \\ Faculty of Sciences and Techniques (FAST), BP: 4521 Cotonou, Benin. \\ ${ }^{2}$ National Laboratory of Pharmacognosy, Benin Center of Scientific and Technical Research (CBRST), \\ BP 06 Oganla, Porto-Novo, Benin. \\ ${ }^{3}$ Louvain Drug Research Institute (LDRI), School of Pharmacy, Université Catholique de Louvain, \\ B1 7203 Av. E. Mounier 72, B-1200 Bruxelles, Belgium. \\ *Corresponding author, E-mail: kpovsalome@yahoo.fr; Tel: +22997883927
}

\begin{abstract}
ABSTRAT
Montmorillonite K-10 was used in the acid catalysis of the Willgerodt-Kindler's reaction (WK) under microwave heating for synthesis of thiobenzamides. Yields of $67 \%$ and $43 \%$ for the synthesis of morpholin-4yl (phenyl) methanethione (1) and [4 - (dimethylamino) phenyl] (morpholin-4-yl) methanethione (2) respectively, showed that the mixture (aldehyde, sulfur, morpholine and K-10) is quite suitable for this reaction. This enables to deduct that the conditions of acid catalysis with the K-10 are favourable to the WK's reaction of carbonyl compounds. Furthermore, yields of $81 \%$ and $74 \%$ respectively for the synthesis of thioamides 1 and 2 in basic catalysis with 4-methylmorpholine allows to confirm that this reaction is more advantageous in basic catalysis. The structures of thioamides synthesized were characterized and confirmed by spectroscopy Infrared (IR), nuclear magnetic resonance $\left({ }^{1} \mathrm{H}\right.$ and $\left.{ }^{13} \mathrm{C} N \mathrm{NMR}\right)$ and mass spectrometry (MS).
\end{abstract}

(C) 2014 International Formulae Group. All rights reserved.

Keywords: Montmorillonite K-10, 4-methylmorpholine, morpholin-4-yl(phenyl)methanethione, [4(dimethylamino)phenyl](morpholin-4-yl)methanethione.

\section{INTRODUCTION}

Sulphur compounds in which there is stability of the functional groups with sulphur in different oxidation states are an interesting family of therapeutics molecules. These compounds are among other thioethers, thioamides, thiosemicarbozones etc. Thioamides, in particular thiobenzamide group, seems to be an interesting pharmacophore in medicinal chemistry, with widespread applications, including the antifungal and antibacterial properties (Matysiak et al., 2000), inhibitors of aldose reductase (Sestani et al., 1984) and receptors of estrogens antagonists (Stauffer et al., 2000; Waisser et al., 2000).

Although many synthetic approaches to prepare thioamides have been previously reported in the literature (Schaumann et al., 1991), the condensation's reaction of the 
carbonyl compound with an amine in the presence of sulphur known as the WillgerodtKindler's reaction (Kindler, 1923; DeTar et al., 1946) is the most used for the synthesis of thioamides (Amupitan, 1983) (Figure 1). One of the interesting characteristics of this reaction lies in the fact that the system behaves as an auto-redox system in which the carbonyl is reduced while the terminal methyl group is oxidized into a thioamide (Dauben et al., 1957; Darabi et al., 2004)

Considering its wide applications, the reaction continues to be the subject of several optimization works. Recently, Gbaguidi et al. (2010) showed that an acid catalyst such as Montmorillonite K-10 is also participated in optimum conditions during its use for the synthesis of 1-morpholino-2-(naphtalen-1yl)ethanethione. The use of this strong acid in the presence of an excess of morpholine (also used as a base), concludes that acid-base catalysis conditions ameliorate the WK's reaction of ketone compounds. This condensation between amines and aldones is governed by the acid-base catalysis (Bruice et al., 1963) which could be beneficial.

In our pursuit to improve the scope of the WK's reaction, we explored the value of the addicting amount of an acid catalytic in heterogeneous phase as montmorillonite $\mathrm{K}$ 10 in the reaction (aldehyde, morphine and sulphur) under microwave heating for the synthesis of thiobenzamides and derivatives and its comparative study with base catalysis with 4-methylmorpholine.

\section{MATERIALS AND METHODS Reagents and catalysts}

Substrates such as benzaldehyde, 4(dimethylamino)benzaldehyde; reagents (sulphur, morpholine) were bought at the chemical PROLABO industries ACROS ORGANICS.

Montmorillonite K-10 and 4methylmorpholine obtained from Sigma Chemical Corporation were used as catalysts during the reactions.
Montmorillonite $\mathrm{K}-10$ is a commercial clay obtained by acidification of the natural Montmorillonite belonging to smectite group of the family of phylosilicates of the formula (Na, Ca) 0.3 ( $\mathrm{Al}, \mathrm{Mg})_{2} \mathrm{Si}_{4} \mathrm{O}_{10}(\mathrm{OH})_{2} \cdot \mathrm{nH}_{2} \mathrm{O}$ (Alas et al., 1994; do Rego et al., 2010).

Similarly, the 4-methylmorpholine is dried by reflux on $\mathrm{KOH}$ during 1 hour followed by distillation at atmospheric pressure.

\section{General techniques}

The synthesis was made under radiation heating in an oven microwave "Brandt type MB 18 T (940W, $2450 \mathrm{MHz})$ ". The evolution of the reagents to products is assessed using a thin layer chromatography (TLC). This TLC was realized on the plates of silica (silica gel 60 F254 Merck TCL) with mobile phase which is a mixture of hexane and ethyl in proportion acetate $(6 \mathrm{v} / 4 \mathrm{v})$ and then revealed to the ultraviolet (UV) light of wavelength $\lambda=254$ nm.

The treatment of the reaction mixture was made with solutions of ethyl acetate, hydrochloric acid, ammonia chloride and distilled water. Indeed, the solubility of the product in ethyl acetate has allowed the elimination of excess sulphur by simple filtration before his treatment other solvents by decantation. The organic phase to ethyl acetate after drying on the crystals of $\mathrm{MgSO}_{4}$, was concentrated with a rotary evaporator at low pressure (pressure in tap water) type 4000 efficient laborota Heidolph.

Thioamides synthesized after recrystallization in ethyl alcohol $95^{\circ}$, were purified on column chromatography with mobile phase which is a mixture of hexane and ethyl in proportion acetate $(6 \mathrm{v} / 4 \mathrm{v})$ and phase stationary silica (Silica gel 63-160 $\mu \mathrm{m}$ ) marketed by PROLABO.

The melting point of synthesized and purified thioamides is made on a fusionometer of type electrothermal 1A 9000, before the characterization and confirmation of their structure by the spectral analysis methods (IR, NMR, MS). The infrared (IR) spectra have 
been recorded using a spectrophotometer (Perkin - Elmer FTIR 286).

The different spectra of Nuclear Magnetic Resonance (NMR) were carried out and recorded using a Bruker $400 \mathrm{MHz}$ for ${ }^{1} \mathrm{H}$ proton and $100 \mathrm{MHz}$ for the carbon ${ }^{13} \mathrm{C}$ in $\mathrm{CDCl}_{3}$ (deuterated chloroform). Regarding the mass spectra in direct introduction and LC/MS (liquid chromatography high performance coupled with mass spectrometry), they were made using a mass spectrometer equipped with an interface of chemical ionization atmospheric pressure (APCI) in positive mode. This technique allowed to determine molecular molar mass and to confirm the purity of synthetic products.

\section{Method of synthesis}

The synthesis of thioamides is made in acid catalysis with Montmorillonite K-10 and basic with 4-methylmorpholine (Figure 2).

\section{Acid Catalysis: Montmorillonite K-10}

In a mixture (5 mmol) of aldehyde and (7.5 mmol) of morpholine put under agitation, $15 \mathrm{~mL}$ of DMF (the solvent) are added. To the mixing under agitation, we are added $0.35 \mathrm{~g}$ of $\mathrm{K}-10$ and $8 \mathrm{mmol}$ of sulphur. The agitation continues until the obtaining a mixture of Brown colour which will be submitted to the microwave heating for about 10-15 minutes in a 10 sequences $(01 \mathrm{~min})$ spaced pulses of 1 minute 20 seconds.

After cooling to room temperature, the mixture is then poured in a solution of ethyl acetate for allowing the elimination of sulphur and K-10 by simple filtration. The filtrate obtained is treated with $100 \mathrm{~mL}$ of hydrochloric acid $(0.1 \mathrm{M})$ to protonate the amine in excess, then with $100 \mathrm{~mL}$ of saturated $\mathrm{NH}_{4} \mathrm{Cl}$ solution and finally washed with $2 \times 100 \mathrm{ml}$ of distilled water. The organic phase after drying over $\mathrm{MgSO} 4$ is concentrated by evaporation.

The formed crystals have recrystallized in ethyl alcohol $95^{\circ}$ before its purification on column to ensure the elimination of sulphur and secondary products. Basic Catalysis: 4-methylmorpholine (4-MM)

A mixture $(5 \mathrm{mmol})$ of aldehyde $(7.5$ mmol ) of morpholine , $8 \mathrm{mmol}$ of sulfur and $0.5 \mathrm{mmol}$ of 4-methylmorpholine in $25 \mathrm{~mL}$ of DMF (solvent) were thoroughly under agitation. The mixture was placed on the rotating plateau of an oven microwave during one minute then allows standing for three minutes. The reaction mixture is again subjected to microwave for approximately 25 sequences of irradiation of 1.5 minutes spaced 3 minutes until a brown colour.

After cooling to room temperature, the mixture is then poured in a solution of ethyl acetate for allowing the elimination of sulphur. The obtained filtrate is washed with $2 \times 100$ $\mathrm{mL}$ of distilled water. The organic phase after drying over $\mathrm{MgSO}_{4}$ is concentrated by evaporation. Left to rest in fridge, the formed crystals have been recrystallized in ethyl alcohol $95^{\circ}$ before its purification on column to ensure the elimination of sulphur and secondary products.

\section{RESULTS}

Two thioamides morpholin-4yl(phenyl)methanethione (1) and [4(dimethylamino) phenyl](morpholin-4yl)methanethione (2) were synthesized with different yields according to the type of catalysis. Indeed, in acid catalysis with Montmorillonite K - 10, the thioamides 1 and 2 gave respectively $67 \%$ and $43 \%$.

Similarly, the synthesis of thioamide $\mathbf{1}$ and $\mathbf{2}$ in basic catalysis with the 4methylmorpholine gave $81 \%$ and $74 \%$ respectively (Table 1 ). The calculated molar mass of $\mathbf{1}$ and $\mathbf{2}$ are $207.07 \mathrm{~g} / \mathrm{mol}$ and 250.11 $\mathrm{g} / \mathrm{mol}$, respectively. The physicochemical characteristics and spectrometric analyses of these thioamides give:

Rf (Hexane / ethyl acetate 6v/4v): 0.71

M.P (melting point): $137-138^{\circ} \mathrm{C}$

MS: $207.06 \mathrm{~m} / \mathrm{z}$

IR $v\left(\mathrm{KBr} \mathrm{cm}^{-1}\right): 3025.16 ; 3009.17 ; 2971.68(\mathrm{C}$

aromatic); $1594.11 ; \quad 1574.71 ; \quad 1495.25$ (thioamide). 
${ }^{1} \mathrm{H}$ NMR $\left(\mathrm{CDCl}_{3}, \delta \mathrm{ppm}\right): 7.3 \quad(5 \mathrm{H}, \mathrm{m}$, aromatic); $4.4\left(2 \mathrm{H}, \mathrm{t}, \mathrm{C}^{1} \mathrm{H}_{2}\right) ; 3.85(2 \mathrm{H}, \mathrm{t}$, $\left.\mathrm{C}^{4} \mathrm{H}_{2}\right) ; 3.6\left(4 \mathrm{H}, \mathrm{t}, \mathrm{C}^{2} \mathrm{H}_{2}, \mathrm{C}^{3} \mathrm{H}_{2}\right)$.

${ }^{13} \mathrm{C}$ NMR $\left(\mathrm{CDCl}_{3}, \delta \mathrm{ppm}\right): 140.6 \quad\left(\mathrm{C}^{1}\right.$ aromatic); $126.99\left(\mathrm{C}^{2}, \mathrm{C}^{6}\right.$ aromatic); 126.66 $\left(\mathrm{C}^{3}, \mathrm{C}^{5}\right.$ aromatic); $123.99\left(\mathrm{C}^{4}\right.$ aromatic $)$; 199.15(C=S); $47.16\left(\mathrm{C}^{1}\right) ; 64.64\left(\mathrm{C}^{2}\right) ; 64.86$ $\left(\mathrm{C}^{3}\right) ; 50.63\left(\mathrm{C}^{4^{\prime}}\right)$.

Rf (Hexane / ethyl acetate 6v /4v): 0.60

M.P: $149-150{ }^{\circ} \mathrm{C}$

MS: $250.12 \mathrm{~m} / \mathrm{z}$

IR $v \quad\left(\mathrm{KBr} \quad \mathrm{cm}^{-1}\right): 3000.38 ; 3020.40 \quad(\mathrm{C}$ aromatic); $2962.64 \quad$ (methyl); 3448.83 (amine); 1547.15; 1520.63; 1487.27 (thioamide)

${ }^{1} \mathrm{H}$ NMR $\left(\mathrm{CDCl}_{3}, \delta \mathrm{ppm}\right): 7.3\left(2 \mathrm{H}, \mathrm{t}, \mathrm{C}^{2} \mathrm{H}\right.$, $\mathrm{C}^{6} \mathrm{H}$ aromatic); $6.7 \quad\left(2 \mathrm{H}, \quad \mathrm{t}, \quad \mathrm{C}^{3} \mathrm{H}, \quad \mathrm{C}^{5} \mathrm{H}\right.$ aromatic); $4.4\left(2 \mathrm{H}, \mathrm{t}, \mathrm{C}^{1} \mathrm{H}_{2}\right) ; 3.8(6 \mathrm{H}, \mathrm{t}$, $\left.\mathrm{C}^{4} \mathrm{H}_{2}, \mathrm{C}^{2} \mathrm{H}_{2}, \mathrm{C}^{3} \mathrm{H}_{2}\right), 3\left(6 \mathrm{H}, \mathrm{s}, 2 \mathrm{CH}_{3}\right)$

${ }^{13} \mathrm{C}$ NMR $\left(\mathrm{CDCl}_{3}, \delta \mathrm{ppm}\right): 129.78\left(\mathrm{C}^{1}\right.$ aromatic); $128.72\left(\mathrm{C}^{2}, \mathrm{C}^{6}\right.$ aromatic); 111.1 $\left(\mathrm{C}^{3}, \mathrm{C}^{5}\right.$ aromatic $) ; 151.24\left(\mathrm{C}^{4}\right.$ aromatic $)$;
$202.25(\mathrm{C}=\mathrm{S}) ; 52.89\left(\mathrm{C}^{1}, \mathrm{C}^{4}\right) ; 66.78\left(\mathrm{C}^{2}\right.$, $\left.\mathrm{C}^{3}\right) ; 40.27\left(2 \mathrm{CH}_{3}\right)$

In infrared spectrometry, the aromatic ring of our thioamides vibrates between frequencies $2971.68-3025.16 \mathrm{~cm}^{-1}$ for $\mathbf{1}$ and $3000.38-3020.4 \mathrm{~cm}^{-1}$ for 2 .

Their corresponding thioamide group vibrates respectively between 1495.25 1594.11 and $1487.27-1547.15 \mathrm{~cm}^{-1}$. The NMR ${ }^{1} \mathrm{H}$ analysis confirms the existence of the deblindes aromatic protons which usually appear around chemical shift $\delta \approx 7 \mathrm{ppm}$. As the NMR ${ }^{13} \mathrm{C}$ which allows us to determine different types of carbon forming the chains of thioamides, the group thioamide of $\mathbf{1}$ and $\mathbf{2}$ shows respectively a chemical shift of 199.15 and 202.25 ppm. In addition, the dimethylamino group bound to the aromatic nucleus of product $\mathbf{2}$ presents chemical shifts of $\delta=3 \mathrm{ppm}$ in the ${ }^{1} \mathrm{H}$ NMR and $\delta=40.27$ ppm ${ }^{13} \mathrm{C}$ NMR.<smiles>S=C(c1ccccc1)N1[C]COCC1</smiles>

1: Morpholin-4-yl (phenyl)methanethione.<smiles>C[C@@H]1CO[CH][CH]N1C(=S)c1ccc(N(C)C)cc1</smiles>

2: [4-(dimethylamino) phenyl] (morpholin-4-yl) methanethione 
<smiles>[R]C(=O)C(C)CC</smiles>

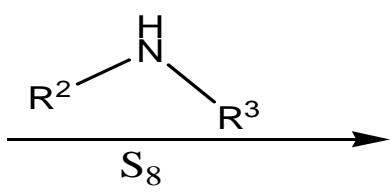<smiles>[R]N([R])C(=S)C(C)(C)C</smiles>

Figure 1: Reaction of Willgerodt-Kindler.

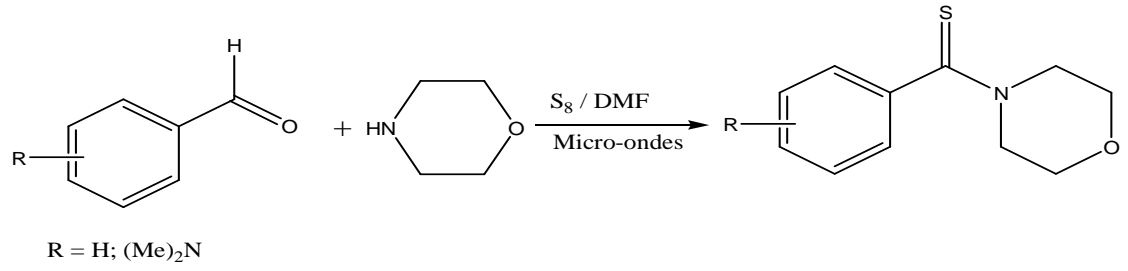

Figure 2: formation of thioamides by the WK's reaction.

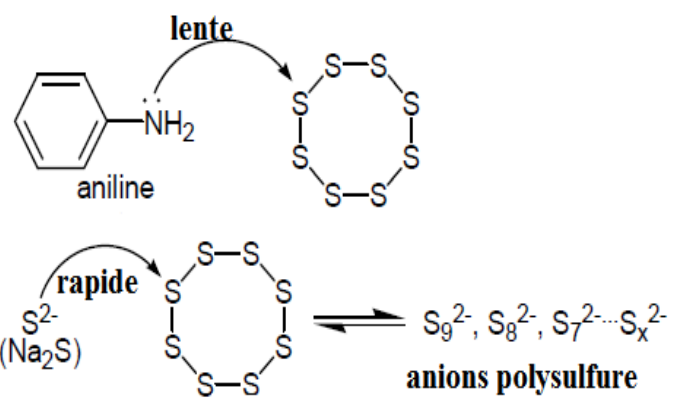

Figure 3: Kinetic of the initiation phase with a basic catalyst $\mathrm{Na}_{2} \mathrm{~S} \cdot 9 \mathrm{H}_{2} \mathrm{O}$ (Okamoto et al., 2009).

Table 1: Yield of synthetized thioamides.

Montmorillonite K-10 4-methylmorpholine

morpholin-4-yl(phenyl)methanethione (1) $67 \%$

\section{DISCUSSION}

The difference between the calculated molecular weight and the molecular weight obtained by mass spectrometry APCI each thioamide is generally of the order of $0.05 \%$ of the calculated mass which confirms partially the structures of the suggested thioamides.

All the data spectrometric of the thioamides synthesized are in accordance with the structures suggested by thioamides $\mathbf{1}$ and 2. Indeed, the frequencies of vibration of 
thioamides in IR between $3030-3050 \mathrm{~cm}^{-1}$ and the chemical shifts in NMR ${ }^{1} \mathrm{H}$ (around $\delta \approx 7$ ppm) revealed the presence of an aromatic ring. Moreover the analysis in $\mathrm{RMN}{ }^{13} \mathrm{C}$ presents a chemical shifts of $\delta=199.15 \mathrm{ppm}$ and $\delta=202.25 \mathrm{ppm}$ for the compound $\mathbf{1}$ and 2 respectively characterizing the group thioamide. These values including those of the group morpholino of our thioamides are quite similar to those obtained by chemdraw calculation and indicated in the literature (Daniel et al., 2009).

The idea of using montmorillonite K10 as acid catalyst is nothing new. Its use is justified not only by the possibility of the formation of an enamine and imine in acid medium, but also the ease of recycling by simple filtration. This appears as an advantage compared to homogeneous phase reactions. Through our work, this catalyst is suitable for the synthesis of thioamides morpholin-4yl(phenyl)methanethione (1) and [4(dimethylamino)phenyl](morpholin-4-

yl)methanethione (2) using microwave heating. To our knowledge, montmorillonite K-10 had never been used to catalyze this synthesis.

The extension of the Willgerodt Kindler's reaction of aldehyde compounds with the catalyst K-10 allows firstly the recovery of acid catalysis of this reaction of carbonyl compounds and from a comparative study between this catalysis and base catalysis. In effect, the work of Kioumars et al. (2007) revealed a high chemoselectivity of derivatives of benzaldehyde on those of acetophenones when using water as a solvent in the WK's reaction. This present work showed that the K-10 used as a catalyst in the reaction of WK for ketone compounds indicated in the work of Gbaguidi et al. (2010) can also be used for derivatives of benzaldehyde with interesting yield. So, with this catalyst $\mathrm{K}-10$, benzaldehyde is the most reactive. It reacts quickly and leads to better performance (> 60\%). But this catalysis may influence the reactivity of the compounds having an amino group bound to the nucleus aromatic 2 (43\%).

A synthesis of thioamides $\mathbf{1}$ and $\mathbf{2}$ in DMF under microwave heating in the presence of another catalyst including a basic catalyst such as 4-methylmorpholine (4-MM) gives yields of $81 \%$ and $74 \%$ respectively. The choice of 4-MM was motivated by its appropriate boiling point and the fact that the tertiary amines by catalyzing the reaction are also subject in sulfuration completes on the methylene in nearby position of the basic nitrogen. This secondary reaction has been minimized during use of 4-MM. (Poupaert et al., 2001, 2004).

A comparative analysis of both catalysts shows that in the presence of K-10, the yield is lowers that with the basic catalyst. The basic catalysis of WK's reaction to the course which takes place in a reaction between sulphur and the amine has been the subject of numerous studies although the behaviour and fate of sulphur in the intermediate reaction have not been elucidated.

Nevertheless, Davis et al. (1962) suggested the formation of anions polysulphides and related ions generated by nucleophilic attack of the amine on the ring of sulphur $\mathrm{S}_{8}$ (Okamoto et al., 2009). In addition, the work of Okamoto et al. (2009) showed that in the presence of a base catalysis, this initiation of nucleophilic cleavage of the ring of sulphur is fast and therefore promotes best performance (Okamoto et al., 2009) (Figure $3)$. As against, acid catalysis may enhance the less nucleophilic attack of the amine on the ring by engaging $S_{8}$ because the amine is engaged in an acid-base reaction. This would explain the low yield of this acid catalysis.

\section{Conclusion}

In recent years, catalytic synthesis methods have generated intense research efforts in the quest to provide scientists the tools to perform a binding of carbon heteroatom with interesting biological properties. These research efforts have created 
a comprehensive list of highly active catalysts that facilitate the synthesis of compounds of greater complexity and reduced steps. Accordingly, the effective constructive ability found during the latest catalyzed methodologies has been a determining factor in the design of the fine chemicals and pharmaceutical building blocks. In itself, as mentioned in the introduction, the reaction of WK has a great potential.

The application to benzaldehyde and 4(dimethylamino)benzaldehyde of the Willgerodt-Kindler's reaction under microwave heating in acid catalysis with Montmorillonite $\mathrm{K}-10$ is valid despite having a less interesting yield that the basic catalysis with 4-methylmopholine. The present contribution opens new perspectives on the scope of the WK's reaction under microwave heating in heterogeneous catalysis acid of carbonyl compounds.

\section{REFERENCES}

Alas M, Gubelmann M, Popa JM. 1994. Process for preparing acid anhydrides by passing a solution of this acid over an acidified clay. European Patent., EP 0317394. Kind Code: B1.

Amupitan J. 1983. Oxidation and reduction. Org Synth., 730.

Bruice TC, Topping RM. 1963. Catalytic Reactions Involving Azomethines. III. The Influence of Morpholine upon the Imidazole Catalysis of the Transamination of Pyridoxal by $\alpha$ Aminophenylacetic Acid. The Transamination of the Morpholine Imine of Pyridoxal. J. Am. Chem. Soc., 85(10): 1493-1496.

Darabi HR, Aghapoor K, Tajbakhsh M. 2004. Extension of the Willgerodt-Kindler Reaction: Protected Carbonyl Compounds as Efficient Substrates for this Reaction. Tetrahedron Lett., 45: 4167-4169.

Dauben WG, Ciula RP, Rogan JB. 1957. Mechanism of the Willgerodt Reaction. Studies with 1-Tetralones. J. Org. Chem., 22(4): 362-365.
Davis RE, Nakshbendi HF. 1962. Sulfur in Amine Solvents. J. Am. Chem. Soc., 84(11): 2085-2090.

DeTar DF, Carmack M. 1946. The Willgerodt Reaction II. A Study of Reaction Conditions with Acetophenone and Other Ketones. J. Am. Chem. Soc., 68(10): 2025 - 2029.

Do Rego T, Kpoviessi DSS, Gbaguidi F, Sagbo E, Yalo NE, Poupaert J, Accrombessi GC. 2010. Tributyrin of transesterification catalyzed by montmorillonite K-10 in the presence of ethanol. Int. J. Biol. Chem. Sci., 4(5): 1501-1508.

Draoui N. 2009. Synthèse, analyses et évaluations pharmacologiques de dévivés thioamides, thiourée et oxothioamides : inhibiteurs potentiels des enzymes de dégradation du système endocannabinoïde. Master en Sciences pharmaceutiques, Université Catholique de Louvain (UCL), Louvain.

Gbaguidi FA, Kapanda C, Ahoussi A, Lambert DM, Accrombessi GC, Mouddachirou M, Poupaert J. 2010. Général Acid-base catalysis in the willgerodt-Kindler Réaction. J. Soc Ouest-Afr. Chim., 029: 89-94.

Kawai Y, Kanbara T, Hasegawa K. 1999. Preparation of polythioamides from dialdehyde and 4,4'trimethylenedipiperidine with sulfur by theWillgerodt-Kindler reaction. J. Polym. Sci. Part A: Polym Chem., 37: 1737-1740.

Kindler K. 1923. Studies on the mechanism of chemical reactions. First essay. Reduction of amides and oxidation of amines. Justus Liebigs Ann. Chem., 431:187-230.

Kioumars A, Farshid M, Golriz K, Hossein RD. 2007. The willgerodt-kindler reaction in water: high chemoselectivity of benzaldehydes over acetophenone. Monatshefte für chemie, 138: 61-65.

Matysiak J, Niewiadomy A, MacikNiewiadomy G, Korniłłowicz T. 2000. Dependence of fungistatic activity of 2,4dihydroxythiobenzanilides on the 
structure and lipophilic nature of the compounds. Eur J Med Chem., 35(4): 393-404.

Okamoto K, Yamamoto T, Rambara T. 2007. Efficient Synthesis of Thiobenzanilides by Willgerodt-Kindler Reaction with Base Catalysts. Synlett., 2667-2690.

Poupaert JH, Kouinidane K, Renard DM, Lambert M, Isa M. 2001. Base Catalysis in the Willgerodt-Kindler Reaction. Org Prep. Proc. Int., 33: 335-340.

Poupaert JH, Duarte S, Colacino E, Depreux P, McCurdy CR, Lambert DM. 2004. Willgerodt-Kindler microwave-enhanced synthesis of thioamides derivatives. Phos Sulf Sil Rel. Elem., 179: 1959-1973.

Schaumann E. 1991. Comprehensive Organic Synthesis, Trost BM, Fleming I (eds). Pergamon Press: Oxford, UK ; 419- 434.

Sestani JK, Bellini F, Fung S, Abraham N, Treasurywala A, Humber L, Simard-
Duquesne N, Dvornik D. 1984. N-[5(trifluoromethyl)-6- methoxy-1naphthalenyl]thioxomethyl]- Nmethylglycine (Tolrestat), a potent, orally active aldose reductase inhibitor. $J$. Med. Chem., 27(3): 255-256.

Stauffer SR, Coletta CJ, Tedesco R, Nishiguch G, Carlson K, Sun J, Katzenellenbogen BS, Katzenellenbogen JA. 2000. Pyrazole Ligands: StructureAffinity/Activity Relationships and Estrogen Receptoralpha-Selective Agonists. J. Med. Chem., 43: 4934-4947.

Waisser K, Gregor J, Kubicovà L, Klimeçovà $\mathrm{V}$, Kumes $\mathrm{J}$, Machaecek M, Kaustovà $\mathrm{J}$. 2000. New groups of antimycobacterial agents: 6- chloro-3-phenyl-4-thioxo-2H1,3-benzoxazine-2(3H)-ones and 6chloro-3-phenyl-2H-1,3-benzoxazine2,4(3H)-dithiones. Eur. J. Med. Chem., 35: 733-741. 